\title{
BASILAR IMPRESSION ASSOCIATED WITH IMPACTED CISTERNA MAGNA, SPASTIC PARAPARESIS AND DISTRESS OF BALANCE
}

To the Editor - It was with great interest that I read the article (Case Report) "Basilar impression associated with impacted cisterna magna, spastic paraparesis and distress of balance" by Gonçalves da Silva et al. ${ }^{1}$. The authors have extensive experience of the neurosurgical treatment of occipitovertebral malformations, with various important papers published both in Brazil and internationally. These include a description of the surgical technique for osteodural-neural decompression of the posterior fossa (Gonçalves da Silva technique) (2,3. $^{2}$.

In the case report, the authors describe a patient with vertigo, brevicollis, nuchal rigidity, distress of balance, spastic paraparesis, marked hyperactive patellar and Achilles reflexes, and diminished pallesthesia of the lower limbs'. In my opinion, it would be helpful if the authors were to define the te rmdistress of balance better, as this would allow a better correlation between the semiological findings and the structural changes in the occipitocervical region as a result of basilar impression associated with impacted cisterna magna. Two questions are thus pertinent: 1 ) Could the term distress of balance have been used because of the $p$ resence of a syndrome of cerebellar ataxia (dystasia, dysbasia, with an ataxic gait evaluated by means of the tandem gait test) associated with the presence of vertigo resulting from impaired vestibular pathways/vestibular nuclei in the cerebellum? 2) Could a syndrome of sensory ataxia (with the presence of Romberg's sign and impaired proprioceptive sensations) have been present, in an associated form or not, in the case in question?

\section{REFERENCES}

1. Gonçalves da Silva JA, Holanda MMA, Leiros MD, Melo LRS, de Araújo AF, de almeida EB. Basilar impression associated with impacted cisterna magna, spastic paraparesis and distress of balance. A rq Neuropsiquiatr 2006;64:668-671.

2. da Silva JA. Basilar impression and Arnold-Chiari malformation. Su rgical findings in 209 cases. Neurochirurgia (Stutgg) 1992:35:189-195.

3. da Silva JA, Brito JC, da Nóbrega PV, Costa MD, de Souza AB. Surgical findings in 260 cases of basilar impression and/or Arnold-Chiari malformation. Arq Neuropsiquiatr 1994;52:363-369.

Hélio A.G. Teive

Professor Adjunto de Neurologia da UFPR

Curitiba PR, Brasil

E-mail: hagteive@mps.com.br

Aurthor's Response - We thank Professor Teive for the careful reading of our paper and his very important comments and analysis.

In the article "basilar impression associated with impacted cisterna magna, spastic parapare s is and distress of balance, this last term was used to characterize the presence of a mild ataxia of the ce rebellar vermis type. This ataxia could have been determined by the compression of the lobulus floculonodularis of the cerebellum, as proposed by Canelas et al. ${ }^{1}$. Otherwise presented the patient vertigo, probleby resulting from impaired vestibular pathways.

\section{REFERENCES}

1. Canelas HM, Zaclis J. Tenuto RA. Contribuição ao estudo das malformações occipito-cervicais, particularmente da impressão basilar. Arq Neuropsiquiatr 1952;10:407-476.

J.A. Gonçalves da Silva 